\title{
HER2 Protein Biomarker Based Sensor Systems for Breast Cancer Diagnosis
}

\author{
Pranjal Chandra*, Pankaj Suman, Monalisa Mukherjee and Prabhanshu Kumar \\ Biomimetic Research Laboratory, Amity Institute of Biotechnology, Amity University Uttar Pradesh, Noida, India
}

Human Epidermal Growth Factor Receptor 2 (HER2) is overexpressed in $10-25 \%$ of breast cancers [1] is a key predictive biomarker and an effective therapeutic treatment target for breast cancer [2]. The vast evidence from various studies indicates that patients with HER2-positive breast cancer have a poorer prognosis than patients with HER2-negative breast cancer, and it requires a extraordinary therapy $[3,4]$. Therefore, identifying the overexpression of HER2 for breast cancer diagnosis and therapy is very important. In recent years, several methods for detecting HER2-positive cancer cells have been developed, which include genomic and proteomic assays, optical assays [5], fluorescence [6], scattering assays [7], direct cell imaging [8]. Most of these techniques are limited to cell detection and are not available for measuring the concentration of serum HER2. Large clinical trials have clearly shown that the best predictive HER2 testing strategy is associated with practical and economic issues [9]. One of the most extensively used method for HER 2 expression analysis if based on Immunohistochemistry (IHC). This method, however, has major technical limitations with the analytical sensitivity, target specificity, capacity to multiplex, and subjectivity in image understanding $[10,11]$. Additionally, considerable discordance between the results of HER2 studies performed in diverse laboratories has been reported [12]. Hence, a Fluorescence in situ Hybridization (FISH) technology is currently used to detect HER2 gene amplification [13] when the IHCbased results are unclear. Although, all these methods mentioned above are in practice in a smaller or larger way to diagnose breast cancer through the detection of HER2, but their miniaturization and onsite analysis is the major concern for the point-of care diagnosis of breast cancer. In this regard, in recent years methods based on sensor systems have been attempted by various researchers for the quick, sensitive, and selective detection of HER2. Among the entire sensor read out devices an electrochemical system method is usually preferred due to the advantages of being portable, simple, easy to use, cost-effective, disposable, and possible method for the lab-on-a-chip diagnostic system [14-17].

A Surface Acoustic Wave (SAW) biosensor for the detection of HER2 in real time was developed by Friederike et al. [18]. The binding between the target molecule and the detector on the sensor surface are detected by measuring the changes in surface wave velocity caused mainly by mass loading in the sensing layer. This assembly enables label-free and direct detection of the breast cancer marker HER-2 at a concentration of $10 \mathrm{ng} / \mathrm{ml}$ (threshold: $13-20 \mathrm{ng} / \mathrm{ml}$ ). A biosensor system coupled with microfluidics has also been attempted to elucidate another sensitive strategy for the HER2 detection. Recently, a new label-free analytical method for the detection of HER2 biomarker in human serum samples by the Opto-Fluidic Ring Resonator (OFRR) has been successfully developed. The OFRR consists of microfluidics and optical ring resonator sensing technology to achieve rapid and label-free HER2 detection in a small and low-cost platform. HER2 proteins were spiked in the serum at varying concentrations which was further detected by the OFRR at clinically appropriate concentrations in serum samples between 13 to $100 \mathrm{ng} / \mathrm{mL}$ in $15-30 \mathrm{~min}$. It was concluded that the developed sensing system will lead to a device that can be used as a diagnostic tool for the detection HER2 protein and monitoring the progression of other disease in a low-cost sensing setup. It is also anticipated that the developed sensing system can be handled by non-professional personals in a diagnostic laboratory [19]. The biosensor technology has also been significantly applied for the targeting and imaging of human HER2 expressing cells and tumors. A new class of engineered diagnostic molecule "affibody"developed by a Swedish biotechnology company, "Affibody AB" has been applied to develop a nanoprobe for the diagnosis of HER2-expressing tumor and cell imaging [20]. The nanoprobes were designed by linking the $\mathrm{N}$-terminus cysteine residue accurately conjugated with maleimidefunctionalized nanoparticles to make nanoparticle-affibody conjugates. It this system near-infrared quantum dots and iron oxide nanoparticles as two representative nanomaterials were used. The in vitro and in vivo study clearly indicated the promise of this nano-conjugate for the quick and selective diagnosis of HER2 expressing cells. In the same year a Piezoelectric Microcantilever Sensor (PEMS) was reported by an American research group lead by Gregory et al. [21,22]. His group successfully demonstrated the detection of both recombinant and naturally occurring HER2 levels $(>2 \mathrm{ng} / \mathrm{mL}$ ) in the serum of breast cancer patients. Another piezoelectric sensor was developed for the realtime, label-free, in situ detection of HER2 protein in diluted serum using the first longitudinal extension mode of a lead Zirconate-Lead Titanate (PZT)/glass PEMS with $\mathrm{H} 3$ single-chain Variable Fragment (scFv) immobilized on the 3-mercaptopropyltrimethoxysilane insulation layer of the PEMS surface. The linear detection range of HER2 was between the concentrations of $6-60 \mathrm{ng} / \mathrm{ml}$ in a diluted human serum [22]. A newly explored nanomaterial, graphene has also been explored for the development of biosensor for the detection of HER2 protein. In this regard, recently and Graphene-Encapsulated Nanoparticles (GEN) has been developed for the selective detection of HER2 [23]. It this case, a novel 2 dimensional GEN was used which significantly increased the electrical conductivity, mechanical flexibility, surface area, chemical and thermal stability of the biosensor for the highly selective detection of HER2 protein with the detection limit of 1pM. Until the start of year 2013, most of the biosensor readout devices were based on antibodies and a very few was based on affibody. Since these detection molecules are chemically protein in nature, hence the stability and long term storage of biosensor based on these molecules is critical. To overcome these critical issues, very recently an aptamer based biosensor was

*Corresponding author: Pranjal Chandra, Biomimetic Research Laboratory Lab: 218 Amity Institute of Biotechnology, Amity University Uttar Pradesh, J-3 Block, Sector-125 Noida- 201303, Gautam Buddha Nagar, UP, India, Tel: +91120-4392644; Fax: +91-120-4392295; Email: pchandra1@amity.edu

Received November 27, 2013; Accepted November 28, 2013; Published December 02, 2013

Citation: Chandra P, Suman P, Mukherjee M, Kumar P (2013) HER2 Protein Biomarker Based Sensor Systems for Breast Cancer Diagnosis. J Mol Biomark Diagn 5:e119. doi:10.4172/2155-9929.1000e119

Copyright: (c) 2013 Chandra P, et al. This is an open-access article distributed under the terms of the Creative Commons Attribution License, which permits unrestricted use, distribution, and reproduction in any medium, provided the original author and source are credited 
fabricated for detection of both HER2 protein and positive breast cancer cells [24]. The biosensor probe was fabricated by covalently immobilizing anti-HER2 onto a nanoconducting film. The hydrazinegold nanoparticles-aptamer bioconjugate was used as the reporter probe. The reductant hydrazine specifically deposits the silver on the biosensor surface, which stained the breast cancer cells /HER2 protein and was visualized easily by the bare eye and an optical microscope. This method exhibited an outstanding diagnosis method for the highly sensitive detection of SK-BR-3 breast cancer cells in human serum samples with a detection limit of 26 cells $/ \mathrm{mL}$. The latest biosensor for the detection of HER2 protein is based on an electrical tracing-assisted silicon dual-microring resonator sensor system [25]. This biosensor relies on the use of a cheap broadband light source as an alternative of a massive and costly tunable laser, which allows the progress of costeffective point-of-care diagnostic devices by considerably lowering the biosensor price and increasing its portability.

\section{Conclusion}

HER2 has emerged as one of the best diagnostic marker for the diagnosis of most frequent cancer in woman i.e. breast cancer. The bottleneck was to develop a very specific and sensitive diagnostic tool that can help in early detection of these cancerous cells with ease. This has been circumvented by development of different kind of biosensor with high degree of sensitivity and specificity and a recent aptamer based biosensor is providing the stability of the diagnostic platform. Future research should be directed towards improvising the merits of these diagnostic platforms for clinical diagnosis of breast cancer to bring an effective change in the management of breast cancer patients.

\section{Acknowledgement}

Pranjal Chandra thanks Amity University Uttar Pradesh, Noida, India for providing the research facility. Monalisa Mukherjee thanks to Department of Science and Technology, Government of India for the financial support.

\section{References}

1. Slamon DJ, Clark GM, Wong SG, Levin WJ, Ullrich A, et al. (1987) Human breast cancer: correlation of relapse and survival with amplification of the HER2/neu oncogene. Science 235: 177-182.

2. Owens MA, Horten BC, Da Silva MM (2004) HER2 amplification ratios by fluorescence in situ hybridization and correlation with immunohistochemistry in a cohort of 6556 breast cancer tissues. Clin Breast Cancer 5: 63-69.

3. Hung MC, Schechter AL, Chevray PY, Stern DF, Weinberg RA (1986) Molecula cloning of the neu gene: absence of gross structural alteration in oncogenic alleles. Proc Natl Acad Sci U S A 83: 261-264.

4. Telli ML, Hunt SA, Carlson RW, Guardino AE (2007) Trastuzumab-related cardiotoxicity: calling into question the concept of reversibility. J Clin Oncol 25 : 3525-3533.

5. Lu W, Arumugam SR, Senapati D, Singh AK, Arbneshi T, et al. (2010) Multifunctional oval-shaped gold-nanoparticle-based selective detection of breast cancer cells using simple colorimetric and highly sensitive two-photon scattering assay. ACS Nano 4: 1739-1749.

6. Li K, Zhan R, Feng SS, Liu B (2011) Conjugated polymer loaded nanospheres with surface functionalization for simultaneous discrimination of different live cancer cells under single wavelength excitation. Anal Chem 83: 2125-2132.

7. Tsai MC, Tsai TL, Shieh DB, Chiu HT, Lee CY (2009) Detecting HER2 on cancer cells by TiO2 spheres Mie scattering. Anal Chem 81: 7590-7596.

8. Gao J, Chen K, Miao Z, Ren G, Chen X, et al. (2011)Affibody-based nanoprobes for HER2-expressing cell and tumor imaging. Biomaterials 32: 2141-2148.

9. Moelans CB, de Weger RA, Van der Wall E, van Diest PJ (2011) Curren technologies for HER2 testing in breast cancer. Crit Rev Oncol Hematol 80 380-392.
10. Gown AM (2008) Current issues in ER and HER2 testing by IHC in breast cancer. Mod Pathol 21 Suppl 2: S8-8S15.

11. Rhodes A, Jasani B, Barnes DM, Bobrow LG, Miller KD (2000) Reliability of immunohistochemical demonstration of oestrogen receptors in routine practice: interlaboratory variance in the sensitivity of detection and evaluation of scoring systems. J Clin Pathol 53: 125-130.

12. Reddy JC, Reimann JD, Anderson SM, Klein PM (2006) Concordance between central and local laboratory HER2 testing from a community-based clinical study. Clin Breast Cancer 7: 153-157.

13. Phillip K, Xinjun L, Tani L, Limin L, Robert B, et al. (2011) Highly sensitive proximity mediated immunoassay reveals HER2 status conversion in the circulating tumor cells of metastatic breast cancer patients. Proteome Sci. 9 : 75.

14. Chandra P, Noh HB, Shim YB (2013) Cancer cell detection based on the interaction between an anticancer drug and cell membrane components. Chem Commun (Camb) 49: 1900-1902.

15. Chandra P, Koh WC, Noh HB, Shim YB (2012) In vitro monitoring of i-NOS concentrations with an immunosensor: the inhibitory effect of endocrine disruptors on i-NOS release. Biosens Bioelectron 32: 278-282.

16. Zhu Y, Chandra P, Song KM, Ban C, Shim YB (2012) Label-free detection of kanamycin based on the aptamer-functionalized conducting polymer/gold nanocomposite. Biosens Bioelectron 36: 29-34.

17. Chandra P, Son NX, Noh HB, Goyal RN, Shim YB (2013) Investigation on the downregulation of dopamine by acetaminophen administration based on their simultaneous determination in urine. Biosens Bioelectron 39. 139-144.

18. Friederike JG, Michael R, Kerstin L (2010) Label-free detection of breast cance marker HER-2/neu with an acoustic biosensor Procedia Engineering 5: 914 917

19. Gohring J T, Paul SD, Xudong F (2010) Detection of HER2 breast cance biomarker using the opto-fluidic ring resonator biosensor. Sensors and Actuators B 146: 226-230.

20. Gao J, Chen K, Miao Z, Ren G, Chen X, et al. (2011)Affibody-based nanoprobes for HER2-expressing cell and tumor imaging. Biomaterials 32: 2141-2148.

21. Loo L, Capobianco JA, Wu W, Gao X, Shih WY, et al. (2011) Highly sensitive detection of HER2 extracellular domain in the serum of breast cancer patients by piezoelectric microcantilevers. Anal Chem 83: 3392-3397.

22. Joseph A C, Wan Y S, Gregory PA, Wei-Heng S (2011) Label-free Her2 detection and dissociation constant assessment in diluted human serum using a longitudinal extension mode of a piezoelectric microcantilever sensor. Sensors and Actuators B 160: 349-356.

23. Myung S, Solanki A, Kim C, Park J, Kim KS, et al. (2011) Graphene-encapsulated nanoparticle-based biosensor for the selective detection of cancer biomarkers. Adv Mater 23: 2221-2225.

24. Zhu Y, Chandra P, Shim YB (2013) Ultrasensitive and selective electrochemical diagnosis of breast cancer based on a hydrazine-Au nanoparticle-aptamer bioconjugate. Anal Chem 85: 1058-1064.

25. Kim KW, Song J, Kee JS, Liu Q, Lo GQ, et al. (2013) Label-free biosensor based on an electrical tracing-assisted silicon microring resonator with a lowcost broadband source. Biosens Bioelectron 46: 15-21. 